\title{
Misdiagnosis of Diverticulitis After a Prior Diagnosis of Irritable Bowel Syndrome (IBS)
}

\author{
George F. Longstreth, MD, Carrie Wong, MD, and Qiaoling Chen, MS
}

Introduction: Irritable bowel syndrome (IBS) and diverticulitis share clinical features. Misdiagnosed diverticulitis can cause unnecessary antibiotic therapy. Among IBS and non-IBS patients, we compared outpatient, clinically diagnosed (no computed tomography) diverticulitis rates. Among primary-care, diverticulitis-diagnosed IBS patients, we assessed imaged diverticulosis and probable misdiagnosed diverticulitis.

Methods: Among 3836-patient IBS and 67,827-patient non-IBS cohorts identified from 2000 to 2002, we retrospectively compared the frequency of outpatient, clinically diagnosed, antibiotic-treated diverticulitis from 2003 to endpoints of December 31, 2017, disenrollment, or death. In IBS patients, we reviewed records of initial, primary care-managed episodes for misdiagnosis.

Results: In 3836 clinically diagnosed IBS and 63,991 non-IBS cohorts, followup (median [interquartile range]) was $12.4(3.9$ to 15.0$)$ years versus $10.2(3.0$ to 15.0$)$ years, respectively $(P<.001)$. The incidence rate/1000 patient-years $(95 \% \mathrm{CI})$ of diagnosed diverticulitis was 14.0 (12.1 to 16.3) and 4.2 (4.0 to 4.5), respectively, (crude incidence rate ratio, $3.3[2.8-3.9] ; P<.001$ ). Of examined features, the diagnosis of IBS was most strongly associated with clinically diagnosed diverticulitis (adjusted incidence rate ratio [95\% CI]; 2.64 [2.21-3.15], $P<.001)$. Of initial diverticulitis diagnoses in 189 IBS patients, objective evidence-based diagnosis revision or exclusion occurred in 12 (6.3\%), including 6 hospitalized; 29 (15.3\%) had colon imaging before and/or afterward without diverticulosis reported; 143 (75.1\%) had image-documented diverticulosis; and 6 (3.2\%) had no imaging.

Conclusions: Outpatient, clinically diagnosed, antibiotic-treated diverticulitis was increased 3 -fold in IBS patients. Primary care clinical misdiagnosis of initial episodes occurred in 1 of 5 patients, but additional misdiagnosis due to misattribution of IBS pain to diverticulitis is suggested. ( $\mathrm{J}$ Am Board Fam Med 2020;33:549-560.)

Keywords: Antibiotics, Diagnostic Errors, Incidence, Irritable Bowel Syndrome, Diverticulitis, Outpatients, Primary Health Care, Retrospective Studies

\section{Introduction}

Irritable bowel syndrome (IBS), a common functional disorder, is clinically diagnosed by typical symptoms and exclusion of organic disease, usually by limited testing. It is characterized by recurrent

This article was externally peer reviewed.

Submitted 17 September 2019; revised 28 January 2020; accepted 29 January 2020.

From the Department of Gastroenterology, Kaiser Permanente-Southern California, San Diego (GFL, CW); Department of Research \& Evaluation, Kaiser PermanenteSouthern California, Pasadena (QC).

Funding: Kaiser Permanente-Southern California internal research funding.

Conflicts of interest: The authors deny any conflicts of interest.

Corresponding author: George F. Longstreth, MD, Department of Gastroenterology, Kaiser PermanenteSouthern California, 4152 Palmetto Way, San Diego, CA 92103 (E-mail: gflongstreth@gmail.com). abdominal pain and disordered bowel habits. ${ }^{1}$ Colonic diverticulosis is also common, but only a minority of patients with it develop acute diverticulitis. ${ }^{2,3}$ Abdominal pain is the most common gastrointestinal symptom prompting outpatient visits, ${ }^{4}$ and diverticulitis is often diagnosed in outpatients. ${ }^{5,6}$ Abdominal pain varies from mild to severe in both $\mathrm{IBS}^{7}$ and diverticulitis, and abdominal tenderness is found with both disorders. ${ }^{1,7-9}$ Furthermore, many patients with diverticulitis report constipation or diarrhea. ${ }^{8,10,11}$ These shared clinical features, the frequent absence of fever and leukocytosis, ${ }^{8}$ and common uncertainty about whether a patient has diverticulosis promote confusion of IBS with diverticulitis. ${ }^{11,12}$ Outpatients diagnosed with diverticulitis are often treated with antibiotics, so misdiagnosis can result in unnecessary antibiotic therapy. 
In a retrospective long-term cohort study, we aimed to 1) compare health examinees with and without IBS regarding the frequency of outpatient clinically diagnosed (no computed tomography), antibiotic-treated diverticulitis and assess associated patient features; and 2) assess imaging reports of diverticulosis, a prerequisite for diverticulitis, and documented misdiagnosis among IBS patients who had an initial primary care diagnosis of diverticulitis.

\section{Methods}

\section{Study Setting, Patients, and Data Sources}

We enrolled consecutive patients $\geq 18$ years of age who had undergone a health screening evaluation during 3 years in the San Diego service area of Kaiser Permanente-Southern California (KPSC), an integrated, prepaid health care system whose members reflect the diversity of Southern California by census. ${ }^{13}$ All KPSC members have a primary care physician. On October 7, 2007 article records were replaced by electronic medical records. Before that date complete records, including radiologic imaging reports, may not have always been available at outpatient visits; beginning then comprehensive electronic records were uniformly available. Electronic databases included the Charlson Morbidity Index (comprised of potentially life-limiting diseases), comprehensive pharmacy dispensing data and diagnosis coding of all patient encounters using the International Classification of Diseases, Ninth Revision (ICD-9) before October 2015 and the International Classification of Diseases, Tenth Revision (ICD-10) thereafter. Coding staff review codes for all emergency department and inpatient encounters and samples of outpatient encounters.

\section{Identification of IBS and Non-IBS Cohorts}

Subjects had previously submitted a self-completed, pre-examination questionnaire eliciting demographic, symptom, and medical/surgical history data, between 2000 and 2002 as part of a separate Institutional Review Board-approved project. ${ }^{14}$ As previously described, we validated a question on whether a physician had diagnosed IBS by comparing the responses with documented physician diagnosis in the medical records. Agreement occurred in $83.6 \%$ of 201 patients $(\kappa=0.82) .{ }^{14}$ Therefore, examinees were placed in the IBS or non-IBS cohorts according to the question response. We excluded patients initially without IBS who were diagnosed with IBS during followup as identified by ICD-9 code 564.1 and ICD-10 code K58.

\section{Identification of Diverticulitis}

We identified diverticulitis from an outpatient ICD-9 code (562.11 or 562.13) or ICD-10 code (K57.20, K57.30, K57.92, or K57.93) and pharmacy dispensing of an antibiotic $\leq 7$ days after diagnosis. The outpatient settings comprised nonhospital offices, including after-hours urgent care clinics. Emergency department visits were not included. Most of the practitioners were primary care physicians, but nurse practitioners and physician assistants working under their supervision likely diagnosed some cases. As previously published, we developed this case finding method in a pilot sample by assessing multiple computerized algorithms based on electronic data, including diagnosis codes, dispensing of antibiotics and pain medication and/ or pain diagnoses, and excluding patients with infections and/or conditions that could mimic diverticulitis. Testing the method in 1502 randomly selected KPSC members revealed a sensitivity of $84.6 \%$ and positive predictive value of $98.1 \%$ for physician-diagnosed diverticulitis in outpatients. ${ }^{15}$ As we assessed only clinically diagnosed diverticulitis, we excluded patients who had undergone computed tomography (CT) of the abdomen and/or pelvis with or without oral contrast $\leq 14$ days before diagnosis, identified by Current Procedural Terminology codes 74176 to $74178,74150,74160$, and 74170 . We assessed the frequency of outpatient, clinically diagnosed, antibiotic-treated diverticulitis diagnosis from January 1, 2003 to December 31, 2017.

\section{Evaluation of the IBS Cohort for Misdiagnosis and Diverticulosis Documentation}

Two gastroenterologists independently reviewed the medical records of patients in the IBS cohort who had an initial episode of outpatient clinically diagnosed, antibiotic-treated diverticulitis. They recorded data from the outpatient visits when the diagnoses were made, including clinical features and leukocyte counts. Fever was defined as temperature $>37.5^{\circ} \mathrm{C}$ and leukocytosis as $>11,500$ leukocytes $/ \mathrm{mm}^{3}$. They searched outpatient visit records, hospitalization summaries, and laboratory and pathology reports following the visit for evidence of a revised diagnosis with changed therapy or exclusion of diverticulitis, the latter requiring 
$\mathrm{CT} \leq 3$ days after diagnosis that revealed no colonic wall thickening, inflammation of peri-colic fat, or other findings of diverticulitis. They recorded all barium enema, flexible sigmoidoscopy, colonoscopy, and abdominopelvic CT procedures performed before and after the diagnosis and considered the patient as having diverticulosis if a single procedure reported diverticulosis of any severity. Patients with multiple imaging tests were classified as having no diverticulosis only if no procedure reported it, either before or after the diagnosis. The reviewers resolved any discrepancies by joint record review.

\section{Statistical Analysis}

We summarized categorical data as percentages and continuous data as mean \pm standard deviation (SD) or median (interquartile range) as appropriate. We compared categorical data with the $\mathrm{c}^{2}$ test and continuous data with the Student's $t$-test. Incidence rates per 1000 patient-years were calculated and corresponding $95 \%$ CIs were estimated using robust Poisson regression. Controlling for age, sex, race/ethnicity, and all other medical and surgical history variables from the patient questionnaires (Table 1), multivariable Poisson regression was fitted to derive the adjusted incidence rate ratio of diverticulitis in the IBS cohort versus the non-IBS cohort. All tests were 2 tailed, and the level of significance was $<.05$. We used SAS statistical software (version 9.4; SAS Institute, Cary NC).

\section{Results}

\section{Patient Features}

Demographic and history features differed between the 3836 subjects in the IBS cohort and the 63,991 subjects in the non-IBS cohort (Table 1), as previously described in the larger cohorts from which they were derived. ${ }^{14}$ Length of followup was 12.4 (3.9 to 15.0) years versus 10.2 (3.0 to 15.0$)$ years in IBS and non-IBS cohorts, respectively $(P<.001)$.

\section{Diverticulitis Diagnosis Frequency and Associations in IBS and non-IBS Coborts}

Of 89,008 examinees, we excluded 21,181 as detailed in Figure 1, yielding 67,827 examinees, 3836 (5.7\%) IBS and 63,991 (94.3\%) non-IBS examinees. Additional exclusions by electronic database criteria yielded 290 IBS individuals with 523 episodes and 1669 non-IBS individuals with 2455 episodes.

At least 1 episode of clinically diagnosed, antibiotic-treated diverticulitis occurred in 290 of 3836 (7.6\%) and 1669 of 63,991 (2.6\%) outpatients with and without IBS, respectively $(P<.001)$. The incidence rate $(95 \% \mathrm{CI})$ per 1000 patient-years of outpatient clinical diagnosis and antibiotic treatment was 14.0 (12.1 to 16.3 ) versus 4.2 (4.0 to 4.5 ) in IBS and non-IBS cohorts, yielding a crude incidence rate ratio of 3.3 (2.8 to 3.9$)(P<.001)$.

Multivariate Poisson regression revealed that of the patient features, IBS was most strongly associated with outpatient diagnosis (Table 2). Age was only negligibly associated, and a race/ethnicity association varied from negative associations in Asians/ Pacific Islanders and blacks to a positive association in Hispanics compared with whites. Frequent headaches, current smoking, hypertension, cholecystectomy, and back surgery were positively associated, and vegetarianism and diabetes were negatively associated. The Charlson Comorbidity Index was not associated with the diagnosis.

\section{Initial Outpatient, Clinically Diagnosed, Antibiotic-} Treated Diverticulitis in the IBS Cobort

To identify initial episodes of diverticulitis during followup in the IBS cohort, we excluded patients electronically from the total 3836-patient IBS cohort for a diverticulitis history, lack of outpatient diagnosis, use of CT and lack of antibiotic treatment, yielding 204 patients (Figure 2). Record review led to exclusion of 15 additional patients, yielding a final cohort of 189 IBS patients with an initial episode (Figure 3). The age (mean SD) at diagnosis was $65 \pm 12.7$ years, and 142 (75.1\%) were female. Clinical and laboratory records were available on all patients. Temperature was recorded on $118(62.2 \%)$ patients. Abdominal pain, tenderness, and fever occurred in 181 of 189 (95.8\%), 176 of $189(93.2 \%)$ and 3 of 118 (2.5\%) patients, respectively. Of $76(40.2 \%)$ patients who had a leukocyte count performed, 26 (34.2\%) had leukocytosis.

\section{Misdiagnosis and Diverticulosis Documentation in the IBS Cobort}

Figure 3 also summarizes patients whose diverticulitis diagnosis was revised or excluded and the results of colon imaging studies. Within 2 weeks after antibiotics were dispensed for diverticulitis, 12 $(6.3 \%)$ patients were found to have objective 
Table 1. Baseline Demographic, Medical, and Surgical Features in 67,827 Examinees with and without IBS (2000-2002)

\begin{tabular}{|c|c|c|c|}
\hline Feature & IBS $(\mathrm{n}=3836)$ & No IBS $(\mathrm{n}=63,991)$ & $P$ Value \\
\hline \multicolumn{4}{|l|}{ Demographic } \\
\hline Age, mean + SD, y & $54.3+14.1$ & $51.0+15.1$ & $<.001$ \\
\hline Sex, $n(\%)$ & & & $<.001$ \\
\hline Male & $1139(29.7)$ & $35,015(54.7)$ & \\
\hline Female & $2697(70.3)$ & $28,976(45.3)$ & \\
\hline Race/ethnicity, $n$ (\%) & & & $<.001$ \\
\hline White & $3026(78.9)$ & $41,215(64.4)$ & \\
\hline Asian & $124(3.2)$ & $5656(8.8)$ & \\
\hline Black & $142(3.7)$ & $3801(5.9)$ & \\
\hline Hispanic & $399(10.4)$ & $10,280(16.1)$ & \\
\hline American Indian & $11(0.3)$ & $177(0.3)$ & \\
\hline Pacific Islander & $22(0.6)$ & $786(1.2)$ & \\
\hline Multiple categories & $112(2.9)$ & $2076(3.2)$ & \\
\hline Education, $n(\%)$ & & & $<.001$ \\
\hline Some high school & $201(5.2)$ & $4518(7.1)$ & \\
\hline Some college & $1993(52.0)$ & $32,307(50.5)$ & \\
\hline College and above & $1642(42.8)$ & $27,166(42.5)$ & \\
\hline \multicolumn{4}{|l|}{ Medical history, $n(\%)$} \\
\hline Charlson Comorbidity Index & & & $<.001$ \\
\hline 0 & $3334(86.9)$ & $57,712(90.2)$ & \\
\hline 1 to 2 & $480(12.5)$ & $5931(9.3)$ & \\
\hline 3 or more & $22(0.6)$ & $348(0.5)$ & \\
\hline Anxious & $1469(38.3)$ & $12,856(20.1)$ & $<.001$ \\
\hline Worried about being ill & $1053(27.5)$ & $10,363(16.2)$ & $<.001$ \\
\hline Depression & $1005(26.2)$ & $7545(11.8)$ & $<.001$ \\
\hline Frequent headaches & $1149(30.0)$ & $10,555(16.5)$ & $<.001$ \\
\hline Smoking & & & $<.001$ \\
\hline Never & $2173(56.6)$ & $36,105(56.4)$ & \\
\hline Past & $1361(35.5)$ & $21,650(33.8)$ & \\
\hline Current & $302(7.9)$ & $6236(9.7)$ & \\
\hline Alcohol & & & $<.001$ \\
\hline Daily & $286(7.5)$ & $5651(8.8)$ & \\
\hline Never, hardly ever & $2321(60.5)$ & $35,085(54.8)$ & \\
\hline Less than daily & $1229(32.0)$ & $23,255(36.3)$ & \\
\hline Vegetarianism & $135(3.5)$ & $995(3.1)$ & .166 \\
\hline Verbal or physical abuse & $791(20.6)$ & $6659(10.4)$ & $<.001$ \\
\hline Sexual abuse & $599(15.6)$ & $4421(6.9)$ & $<.001$ \\
\hline Diabetes & $185(4.8)$ & $3088(4.8)$ & .993 \\
\hline Fibromyalgia & $309(8.1)$ & $698(1.1)$ & $<.001$ \\
\hline Hypertension & $1244(32.4)$ & $16,887(26.4)$ & $<.001$ \\
\hline Painful intercourse* & $411(15.2)$ & $2681(9.3)$ & $<.001$ \\
\hline Chronic pelvic pain* & $164(6.1)$ & $627(2.2)$ & $<.001$ \\
\hline Painful urination* & $111(4.1)$ & $610(2.1)$ & $<.001$ \\
\hline Frequent urination* & $1034(38.3)$ & $6902(23.8)$ & $<.001$ \\
\hline Irregular periods* & $383(14.2)$ & $4259(14.7)$ & .485 \\
\hline Painful periods* & $260(9.6)$ & $2902(10.0)$ & .535 \\
\hline
\end{tabular}


Table 1. Continued

\begin{tabular}{lccr}
\hline Feature & IBS $(\mathrm{n}=3836)$ & No IBS $(\mathrm{n}=63,991)$ & $P$ Value \\
\hline Surgical history, $n$ (\%) & & & $<.001$ \\
Cholecystectomy & $487(12.7)$ & $2617(4.1)$ & $<.001$ \\
Appendectomy & $837(21.8)$ & $7731(12.1)$ & $<.001$ \\
Hysterectomy* & $920(34.1)$ & $5206(18.0)$ & $<.001$ \\
Back surgery & $174(4.5)$ & $1926(3.0)$ & .105 \\
Coronary artery surgery & $118(3.1)$ & $1691(2.6)$ & .207 \\
Peptic ulcer surgery & $19(0.5)$ & $235(0.4)$ & \\
\hline
\end{tabular}

IBS, irritable bowel syndrome; SD, standard deviation.

${ }^{*}$ Results from women only.

evidence of another etiology for their presenting features (11) or lack of diverticulitis on CT (1). As detailed in Table 3, diseases in the 11 patients were Clostridium difficile colitis (2), urinary tract infection (2), Crohn's disease (2), cholecystitis (1), small bowel obstruction (1), sigmoid volvulus (1), and ovarian cyst (1), and cholecystitis and pancreatitis (1). Six of the patients were hospitalized, and all 12 survived. CT was performed in 3 additional patients 1 to 7 days after diagnosis, which confirmed diverticulitis in all.

Twenty-nine (15.3\%) patients had no diagnosis revision, but they had colon imaging that did not reveal diverticulosis before and/or after diagnosis. As detailed in Appendix, the age of these patients ranged from 25 to 84 years, 26 (89.7\%) were female, and at least 1 procedure revealing no diverticulosis occurred before, after or both before and after diagnosis in 5, 15, and 9 patients, respectively. Nineteen $(65.5 \%)$ patients had $>1$ negative procedure, including 11 who underwent $\geq 3$ procedures.

Combined with the revised diagnoses or CT exclusion of diverticulitis in 12 patients, a lack of diverticulosis on imaging supported misdiagnosis in 41 of $189(21.7 \%)$ patients. One hundred forty-two $(75.1 \%)$ patients (age $66.3 \pm 11.4$ years; 58 [40.8\%] < 65 years; 102 [71.8\%] female) had a diagnosis that was not revised nor excluded by CT and had imaging before and/or after the episode that revealed diverticulosis. Six $(3.2 \%)$ had no colon imaging.

\section{Discussion}

In this retrospective, long-term, cohort study of health examinees, patients with an IBS diagnosis had a 3 -fold increase in the frequency of outpatient, clinically diagnosed and antibiotic-treated diverticulitis compared with those without IBS. Of the features assessed in association with diverticulitis, the strongest association was found with diagnosis of IBS. In patients with IBS and an initial episode of diverticulitis managed in primary care, diagnosis revision and changed therapy occurred in $6.3 \%$ of patients. An additional $15.3 \%$ of patients had colon imaging studies before and/or after the diagnosis that reported no diverticulosis. These findings support misdiagnosis in 1 of 5 patients.

Published evidence is lacking to support such a strong association between IBS and diverticulitis, as we found. An association was reported between IBS, especially diarrhea-predominant IBS, and diverticulosis only in patients aged $\geq 65$ years, but not with diverticulitis. ${ }^{16}$ Another survey found an association between IBS and diverticulosis only in patients $>60$ years but did not assess diverticulitis. ${ }^{17} \mathrm{We}$ did not determine bowel habit predominance; $40.8 \%$ who had diverticulosis diagnosed and lacked evidence of misdiagnosis were $<65$ years when initially treated for diverticulitis. Therefore, it seems unlikely that increased diverticulosis alone explained the 3 -fold increased rate of physician-diagnosed diverticulitis in the IBS cohort.

Diagnosis of diverticulitis in our IBS cohort was primarily based on abdominal pain and tenderness, as fever and leukocytosis were infrequent. Surgeons have also reported on the scarcity of objective evidence of diverticulitis diagnosed in most clinic patients and suggested that many outpatients have mild disease or no diverticulitis at all. ${ }^{6,18}$ However, we are unaware of other investigations that compared the frequencies of the outpatient clinical diagnosis of diverticulitis in patients with and without 
Figure 1. Flowchart summarizing derivation of the cohorts with and without irritable bowel syndrome by electronic database criteria. *Number of unique patients/number of episodes. Abbreviations: CT, computed tomography; IBS, irritable bowel syndrome.

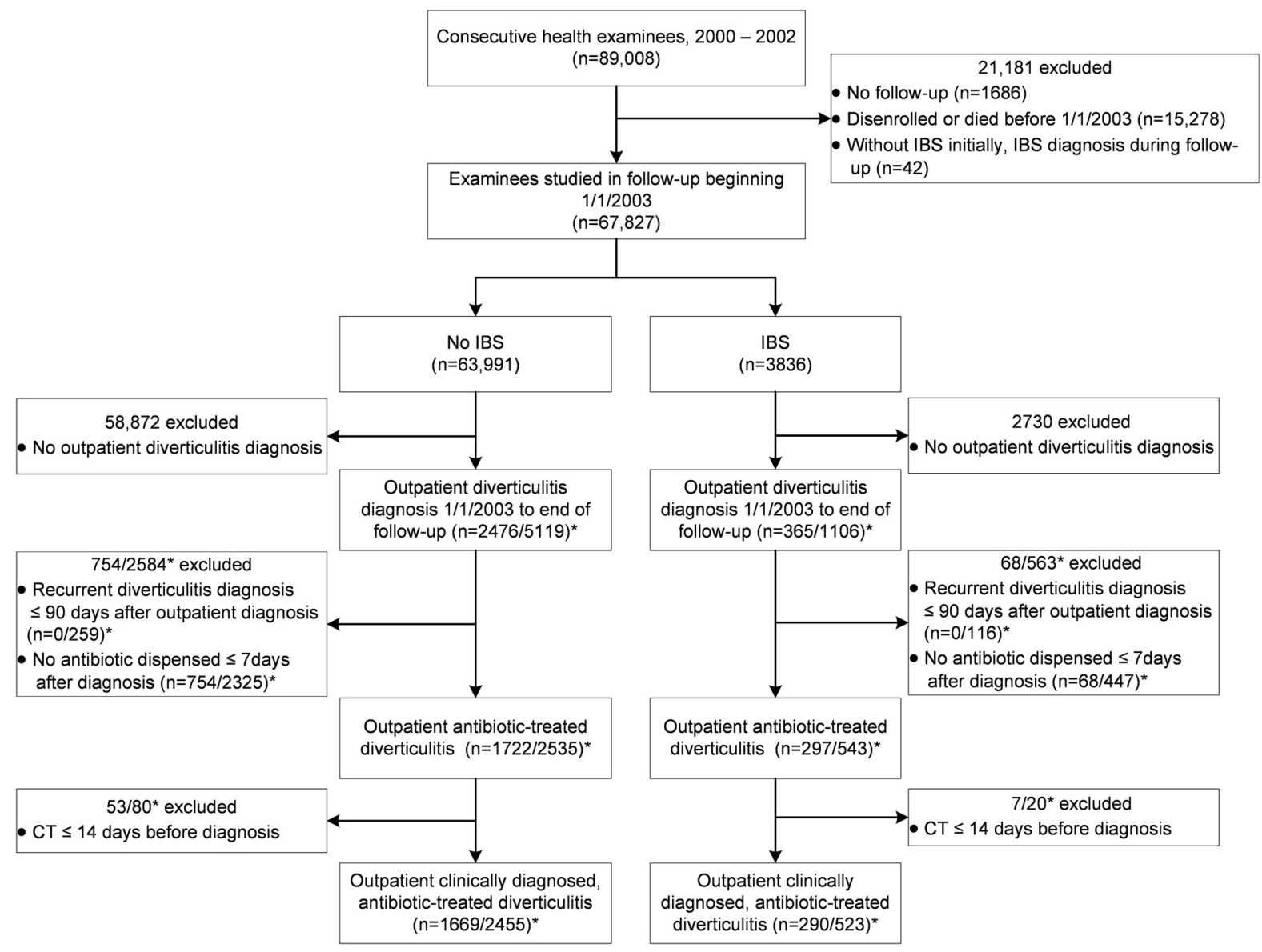

IBS or attempted to document misdiagnosis in IBS patients.

Some of the patients had life-threatening disorders. Other patients lacked diagnosis revision or CT exclusion of diverticulitis and had colon imaging, two thirds with multiple procedures, without a report of diverticulosis.

These 2 types of misdiagnosis may not fully explain the greatly increased diverticulitis frequency in IBS patients. Just as increased abdominal and pelvic surgery in the IBS cohort was attributed to symptom misattribution, ${ }^{14}$ abdominal pain and tenderness could have been incorrectly attributed to diverticulitis. Such misattribution was proven in only 1 case, but few patients had CT before symptoms resolved to allow this assessment, which is typical in outpatient settings. There is evidence of a deficiency in physician awareness of features of IBS patients, including their health care-seeking beha-

vior. Surveys of American ${ }^{19}$ and European ${ }^{20}$ primary care physicians revealed only a minority knew important aspects of IBS or used the Rome diagnostic criteria. About three quarters of American primary care physicians regarded IBS as a diagnosis of exclusion and relied less on symptoms and ordered more tests than specialists. ${ }^{21}$ To our knowledge, primary care physicians' awareness of abdominal tenderness in IBS has not been systematically studied, although a landmark publication almost 60 years ago $^{7}$ detailed tenderness in over $60 \%$ of patients. Furthermore, patient reactions to abdominal palpation can help distinguish functional from structural disorders. ${ }^{22}$

Limitations include our inability to identify which IBS patients with diverticulosis and no other etiology evident for their acute symptoms, had diverticulitis versus a flare of IBS or another disorder. We cannot exclude the possibility that IBS was 
Table 2. Patient Features Associated with Clinically Diagnosed Diverticulitis in 1959 Examinees, 290 with IBS and 1669 Without IBS, During Followup (2003 to 2017)

\begin{tabular}{lccr}
\hline Feature & $\begin{array}{c}\text { Adjusted } \\
\text { IRR }\end{array}$ & 95\% CI & PValue \\
\hline Irritable bowel syndrome & 2.64 & 2.21 to 3.15 & $<.001$ \\
Age, y & 1.02 & 1.01 to 1.02 & $<.001$ \\
Race/ethnicity & & & $<.001$ \\
$\quad$ White & & Reference & \\
Asian/Pacific Islander & 0.62 & 0.49 to 0.79 & $<.001$ \\
Black & 0.73 & 0.54 to 1.00 & .047 \\
Hispanic & 1.53 & 1.29 to 1.83 & $<.001$ \\
Other & 1.04 & 0.75 to 1.18 & .817 \\
Frequent headaches & 1.46 & 1.25 to 1.70 & $<.001$ \\
Smoking & & & .028 \\
Never & & Reference & \\
$\quad$ Past & 1.17 & 0.96 to 1.48 & .106 \\
Current & 1.16 & 1.03 to 1.31 & .012 \\
$\quad$ Vegetarianism & 0.65 & 0.45 to 0.93 & .020 \\
Diabetes & 0.69 & 0.53 to 0.91 & .007 \\
Hypertension & 1.35 & 1.19 to 1.54 & $<.001$ \\
Cholecystectomy & 1.47 & 1.18 to 1.85 & .001 \\
Back surgery & 1.41 & 1.09 to 1.81 & .009 \\
\hline
\end{tabular}

IRR, incidence rate ratio; IBS, irritable bowel syndrome; CI, confidence interval.

incorrectly diagnosed and that in follow-up diverticulitis was mimicked by another disease or coexisted with it, such as the Crohn's disease in 2 patients; however, most of the misdiagnoses were acute diseases. Symptoms of patients attributed to IBS are infrequently changed to another etiology over the long term. ${ }^{23}$ The high prevalence of diverticulosis and usual requirement of CT to confirm diverticulitis challenge any study of clinically diagnosed diverticulitis, retrospective or prospective. The predominant bowel pattern of the IBS patients was not determined, but all subtypes are characterized by abdominal pain. ${ }^{1}$ We did not investigate misdiagnosis in subjects without IBS.

Strengths of the study include large cohorts with validated methods of identifying physician-diagnosed IBS $^{14}$ and diverticulitis ${ }^{15}$ that were assessed for a median of at least 10 years. We utilized comprehensive databases in a prepaid health care system, double-physician record review and objective evidence for revised diagnoses and exclusion of diverticulitis. We had computerized laboratory, radiology, pathology, physician diagnosis, and other data on all patients, enabling us to detect revised diagnoses by objective criteria. Agreement rates between colon imaging procedures range from $60 \%$ to $82 \%$, but we accepted the presence or absence of diverticulosis revealed by any colon imaging procedure. ${ }^{18}$ We required absence of diverticulosis of any severity from all colon imaging studies in IBS patients with multiple procedures before and/or after initial diverticulitis diagnosis to classify them as not having diverticulosis. With this method, we considered some patients as having diverticulosis if an imaging test revealed diverticulosis several years after their initial diverticulitis diagnosis, even if multiple prediagnosis procedures reported no diverticulosis. Patients with negative imaging before initial diagnosis and no subsequent imaging could have developed diverticulosis before diagnosis. However, three quarters of patients classified as without diverticulosis had none reported on imaging after or both before and after diagnosis. Therefore, our strict definition of absent diverticulosis at any time likely classified some patients as having diverticulosis who did not have the disorder when diverticulitis was diagnosed. To minimize potential diagnostic bias related to a prior outpatient diagnosis, we assessed only the initial episodes in the IBS cohort. Our

Figure 2. Flowchart summarizing derivation by electronic database criteria of the subcohort of irritable bowel syndrome patients who had an initial episode of outpatient clinically diagnosed, antibiotic-treated diverticulitis during followup (2003 to 2017). Abbreviations: CT, computed tomography; IBS, irritable bowel syndrome.

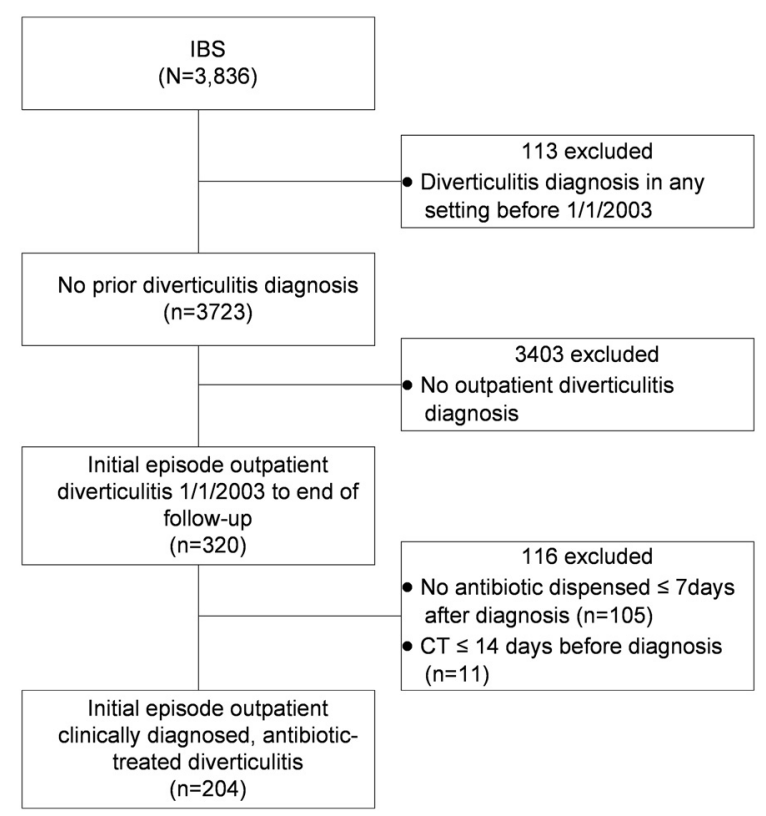


Figure 3. Flowchart summarizing further derivation by record review of the subcohort of irritable bowel syndrome (IBS) patients who had an initial episode of outpatient clinically diagnosed, antibiotic-treated diverticulitis during follow-up (2003 to 2017). Patients are classified according to revision or exclusion of the diagnosis, colon imaging and diverticulosis documentation.

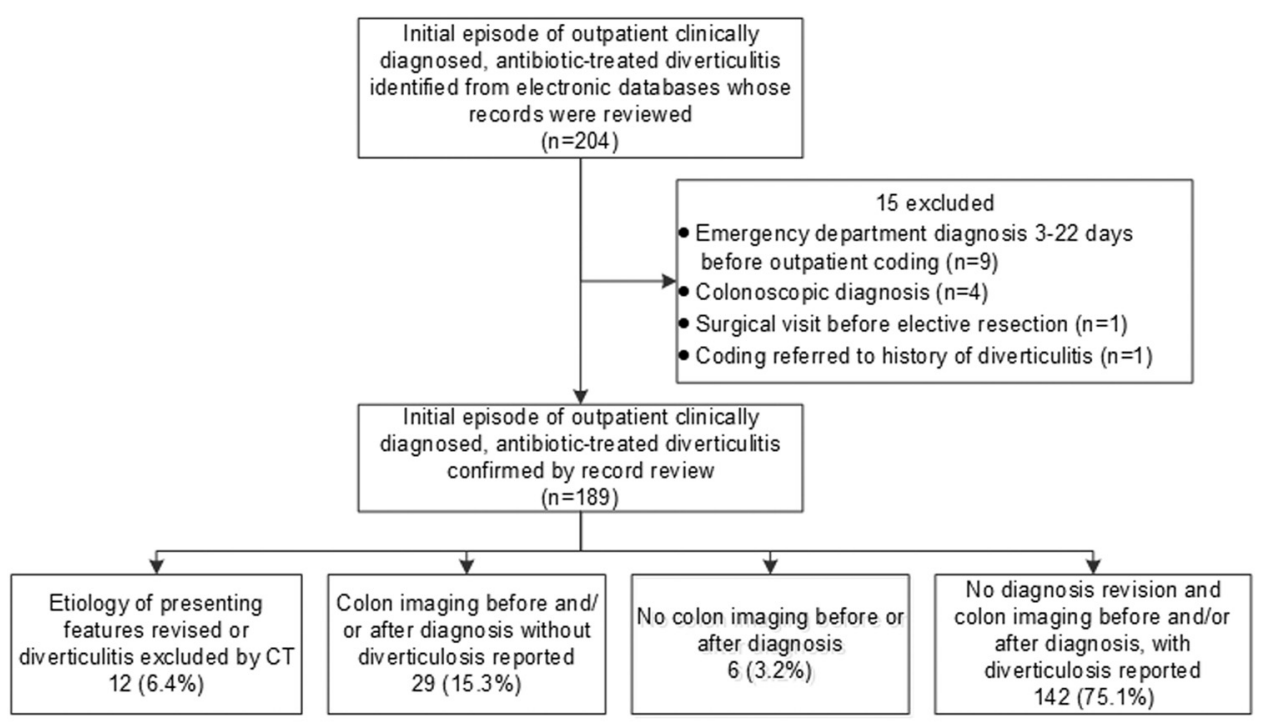

findings seem generalizable because similar proportions (about 70\%) of diagnosed patients are managed as outpatients in our health care system and in a university system, ${ }^{5,6}$ and most outpatients with abdominal pain initially present to primary physicians.

Our findings are relevant to research and practice. Studies in which case finding includes outpatient clinical diagnoses could overestimate cases. In patients with chronic recurrent pain, physicians should be circumspect when a patient reports pain that was previously attributed to diverticulitis from clinical features alone.

Accepted practice calls for physicians to consider how IBS patients' abdominal pain and associated symptoms compare with their usual recurrent symptoms. Consideration of the psychosocial background and prior health care-seeking behavior, including amplified reporting of multiple symptoms and consultation ${ }^{24,25}$ is particularly important in patients with severe pain. ${ }^{26,27}$ However, based on clinical and laboratory findings alone ${ }^{8}$ both primary physicians and gastroenterologists will be uncertain as to whether some patients have diverticulitis.

How should physicians manage IBS patients with suspected diverticulitis? The American Gastroenterological Association suggested selective rather than the traditional routine use of antibiotics in uncomplicated diverticulitis, ${ }^{28}$ and additional data supported the safety of management without antibiotics. ${ }^{29}$ Although mistaken diagnosis of diverticulitis in IBS patients likely represents a minority of all outpatients treated for diverticulitis, avoiding antibiotic use in suspected diverticulitis would reduce the increased rates of antibiotic use and Clostridium difficile infection that we previously documented in the IBS cohort. ${ }^{30}$ Routine antibiotic treatment of diverticulitis may be more likely in the United States than in England where antibiotic use and Clostridium difficile infection have decreased. ${ }^{31}$ It is prudent to manage selected outpatients with close observation and without antibiotics after careful clinical evaluation and relevant laboratory testing. The mean duration of episodically increased abdominal pain in IBS is 3 days. ${ }^{32}$ Failure to improve could lead to consideration of other tests and/or antibiotic treatment.

In conclusion, diverticulitis was diagnosed much more often in outpatients with IBS than those without IBS. This finding was partly attributable to mistaken attribution of presenting features of other diseases to diverticulitis. In other patients, absence of diverticulosis indicated misdiagnosis. Although the findings revealed misdiagnosis in about 1 of 5 patients, we speculate that additional patients had misattribution of abdominal pain and tenderness to 
Table 3. Twelve Patients with Irritable Bowel Syndrome Whose Diagnosis of Diverticulitis Was Subsequently Revised or Excluded (2003 to 2017)

\begin{tabular}{|c|c|c|c|}
\hline $\begin{array}{l}\text { Case \# } \\
\text { Age Sex }\end{array}$ & $\begin{array}{l}\text { Presenting Features and Therapy of } \\
\text { Clinically Diagnosed Diverticulitis }\end{array}$ & Prior Colon Imaging & $\begin{array}{c}\text { Later Events, Revised Diagnosis, } \\
\text { Therapy and Outcome }\end{array}$ \\
\hline $\begin{array}{l}1 \\
6 \mathrm{~F}\end{array}$ & $\begin{array}{l}\text { Abdominal pain, diarrhea } \times 3 \text { weeks, } \\
\text { generalized abdominal tenderness. } \mathrm{T} \\
36.6^{\circ} \mathrm{C} \text {, Long-term cephalexin usage } \\
\text { for cystitis. } \\
\text { Leukocytes } 7900 / \mathrm{mm}^{3} \text {. } \\
\text { Ciprofloxacin } / \text { metronidazole. }\end{array}$ & $\begin{array}{l}\text { Barium enema } 8 \text { years } \\
\text { before- } \\
\text { diverticulosis }\end{array}$ & $\begin{array}{l}\text { Hospitalized } 2 \text { days later, diarrhea and } \\
\text { weakness. } \\
\text { CT-no diverticulitis, } \\
\text { C. difficile toxin-positive colitis, acute } \\
\text { renal failure. } \\
\text { Vancomycin-recovered. } \\
\text { IBS symptoms during } 4.3 \text {-year followup. }\end{array}$ \\
\hline $\begin{array}{l}2 \\
90 \mathrm{~F}\end{array}$ & $\begin{array}{l}\text { Diarrhea, mild LLQ pain } \times 1 \text { week. Took } \\
\text { amoxicillin or cephalexin daily in cycles } \\
\text { until } 10 \text { weeks before, then took } \\
\text { vancomycin for unproven } C \text {. Difficile } \\
\text { infection until } 2 \text { weeks before. T } 36.8^{\circ} \\
\text { C, LLQ tenderness. } \\
\text { Leukocytes } 11,600 / \mathrm{mm}^{3} \text {. } \\
\text { Ciprofloxacin/metronidazole. }\end{array}$ & $\begin{array}{l}\text { CT } 0.4 \text { years before, } \\
\text { barium enema } \\
8.3 \text { years before- } \\
\text { diverticulosis }\end{array}$ & $\begin{array}{l}\text { Hospitalized } 2 \text { weeks later, severe bloody } \\
\text { diarrhea. } \\
\text { CT-sigmoid/descending colon wall } \\
\text { thickening. Flexible sigmoidoscopy- } \\
\text { severe pseudomembranous colitis. } \\
\text { C. difficile toxin-positive. } \\
\text { Vancomycin-recovered. } \\
\text { Recurrent antibiotic-induced } C \text {. difficile } \\
\text { diarrhea before death from heart } \\
\text { failure } 4.7 \text { years later. }\end{array}$ \\
\hline $37 \mathrm{~F}$ & $\begin{array}{l}\text { Low abdominal pain } \times 2 \text { days. } \\
\text { T } 36.9^{\circ} \mathrm{C}, \mathrm{LLQ} \text { tenderness. } \\
\text { Leukocytes } 9900 / \mathrm{mm}^{3} \text {. } \\
\text { Amoxicillin/metronidazole. }\end{array}$ & $\begin{array}{l}\text { Barium enema } 6 \text { years } \\
\text { before- } \\
\text { diverticulosis }\end{array}$ & $\begin{array}{l}\text { Urinalysis-urinary tract infection. } \\
\text { Therapy changed: Ciprofloxacin/ } \\
\text { metronidazole later the same day- } \\
\text { recovered. Diverticulitis diagnosed } \\
\text { clinically again } 4.1 \text { year later. IBS } \\
\text { symptoms during 11-year followup. }\end{array}$ \\
\hline $\begin{array}{l}4 \\
81 \mathrm{~F}\end{array}$ & $\begin{array}{l}\text { Low abdominal pain } \times 1 \text { day. } \\
\text { T } 37.4^{\circ} \mathrm{C} \text {, low abdominal tenderness. } \\
\text { Leukocytes } 12,700 / \mathrm{mm}^{3} \text {. } \\
\text { Ciprofloxacin/metronidazole }\end{array}$ & $\begin{array}{l}\text { CT } 0.3 \text { year before, } \\
\text { colonoscopy } 0.4 \text { year } \\
\text { before, barium } \\
\text { enema } 11 \text { years } \\
\text { before- } \\
\text { diverticulosis }\end{array}$ & $\begin{array}{l}\text { Urinalysis-urinary tract infection. } \\
\text { Therapy changed: Amoxicillin } \\
\text { clavulanate } 6 \text { days later-recovered. } \\
\text { Diverticulitis diagnosed clinically } \\
\text { again } 0.2 \text { year later. Died from cancer } \\
2.6 \text { years later. }\end{array}$ \\
\hline $\begin{array}{l}5 \\
48 M\end{array}$ & $\begin{array}{l}\text { LLQ pain, urgency, bloody stool } \times 4 \text { days. } \\
\text { T } 37.1^{\circ} \mathrm{C} \text {, LLQ tenderness. } \\
\text { Leukocytes } 8400 / \mathrm{mm}^{3} \text {. } \\
\text { Ciprofloxacin } / \text { metronidazole. }\end{array}$ & None & $\begin{array}{l}\text { CT } 2 \text { days later-sigmoid wall } \\
\text { thickening without diverticulosis. } \\
\text { Symptoms persisted. Colonoscopy } \\
3.5 \text { months later-colitis. Drug } \\
\text { therapy-refractory. Proctocolectomy } \\
\text { (Crohn's disease) 2.6 years later. } \\
\text { Stable during 10.8-year followup. }\end{array}$ \\
\hline $\begin{array}{l}6 \\
36 \mathrm{~F}\end{array}$ & $\begin{array}{l}\text { Abdominal pain, diarrhea } \times 3 \text { weeks. } \mathrm{T} \\
36.3^{\circ} \mathrm{C} \text {, low abdominal tenderness. } \\
\text { Leukocyte count not done. } \\
\text { Ciprofloxacin/metronidazole. }\end{array}$ & None & $\begin{array}{l}\text { Flexible sigmoidoscopy } 6 \text { days later- } \\
\text { Crohn's disease. Erythema nodosum, } \\
\text { arthritis } 8 \text { days later. Drug therapy- } \\
\text { did well during 2.4-year followup. }\end{array}$ \\
\hline $\begin{array}{l}7 \\
89 \mathrm{~F}\end{array}$ & $\begin{array}{l}\text { "LLQ pain" } \times 3 \text { days, history of } \\
\text { cholecystitis. T } 37.5^{\circ} \mathrm{C} \text {, "LLQ } \\
\text { tenderness." On penicillin for dental } \\
\text { disease. } \\
\text { Leukocytes } 8600 / \mathrm{mm}^{3} \text {. } \\
\text { Metronidazole added. }\end{array}$ & $\begin{array}{l}\text { Colonoscopy } 2.1 \text { year } \\
\text { before, CT } 2.4 \text { years } \\
\text { before- } \\
\text { diverticulosis. }\end{array}$ & $\begin{array}{l}\text { Hospitalized } 12 \text { hours later, pain worse. } \\
\text { Surgeon noted mid-abdominal pain, } \\
\text { epigastric tenderness. Ultrasound-- } \\
\text { gallstones, gallbladder wall thickened } \\
\text { cholecystitis. Amoxicillin } \\
\text { clavulanate-recovered. Occasional } \\
\text { low abdominal pain until death from } \\
\text { pneumonia } 2.5 \text { years later. }\end{array}$ \\
\hline $87 \mathrm{M}$ & $\begin{array}{l}\text { Left abdominal pain } \times 1 \text { day, history of } \\
\text { metastatic ileal carcinoid and } 2 \text { episodes } \\
\text { small bowel obstruction. T } 36.8^{\circ} \mathrm{C} \text {, left } \\
\text { abdominal tenderness. } \\
\text { Leukocytes } 6700 / \mathrm{mm}^{3} \text {. } \\
\text { Ciprofloxacin } / \text { metronidazole. }\end{array}$ & $\begin{array}{l}\text { CT } 1.2 \text { years before, } \\
\text { colonoscopy } \\
7.2 \text { years before-no } \\
\text { diverticulosis. }\end{array}$ & $\begin{array}{l}\text { Hospitalized } 1 \text { day later, pain worse, } \\
\text { CT-small bowel obstruction. } \\
\text { Resolved. Death from carcinoid } \\
2.3 \text { years later. }\end{array}$ \\
\hline $\begin{array}{l}9 \\
81 \mathrm{~F}\end{array}$ & $\begin{array}{l}\text { Low abdominal pain, diarrhea } \times 10 \text { days. } \\
\mathrm{T} 36.7^{\circ} \mathrm{C} \text {, low abdominal tenderness. } \\
\text { Leukocyte count not done. } \\
\text { Ciprofloxacin. }\end{array}$ & $\begin{array}{l}\text { Barium enema } \\
9.5 \text { years before-no } \\
\text { diverticulosis }\end{array}$ & $\begin{array}{l}\text { Hospitalized } 5 \text { days later, pain worse. } \\
\text { CT-sigmoid volvulus. Colonoscopic } \\
\text { detorsion-recovered. No visits for } \\
\text { abdominal pain until death from } \\
\text { cancer } 1.7 \text { years later. }\end{array}$ \\
\hline
\end{tabular}


Table 3. Continued

\begin{tabular}{|c|c|c|c|}
\hline $\begin{array}{l}\text { Case \# } \\
\text { Age Sex }\end{array}$ & $\begin{array}{l}\text { Presenting Features and Therapy of } \\
\text { Clinically Diagnosed Diverticulitis }\end{array}$ & Prior Colon Imaging & $\begin{array}{c}\text { Later Events, Revised Diagnosis, } \\
\text { Therapy and Outcome }\end{array}$ \\
\hline $\begin{array}{l}10 \\
50 \mathrm{~F}\end{array}$ & $\begin{array}{l}\text { LLQ pain } \times 1 \text { day. T } 36.4^{\circ} \mathrm{C}, \mathrm{LLQ} \\
\text { tenderness. } \\
\text { Leukocytes } 9800 / \mathrm{mm}^{3} \text {. } \\
\text { Ciprofloxacin } / \text { metronidazole. }\end{array}$ & $\begin{array}{l}\text { Flexible sigmoidoscopy } \\
1.4 \text { years before, } \\
\text { colonoscopy } \\
0.8 \text { years before-no } \\
\text { diverticulosis. }\end{array}$ & $\begin{array}{l}\text { To ED } 2 \text { days later, pain persistent. } \\
\text { CT-4.6-cm left ovarian cyst. } \\
\text { Oophorectomy (cystadenoma) } 6 \text { weeks } \\
\text { later. No visits for abdominal pain } \\
\text { during 4-year followup. }\end{array}$ \\
\hline $\begin{array}{l}11 \\
67 M\end{array}$ & $\begin{array}{l}\text { Mid-abdominal pain, } \times 1 \text { day. } \mathrm{T} 37.1^{\circ} \mathrm{C} \text {, } \\
\text { "LLQ tenderness." Leukocytes } 15,300 / \\
\mathrm{mm}^{3} \text {. } \\
\text { Ciprofloxacin/metronidazole }\end{array}$ & $\begin{array}{l}\text { Colonoscopy } 0.7 \text { years } \\
\text { before- } \\
\text { diverticulosis }\end{array}$ & $\begin{array}{l}\text { Hospitalized } 13 \text { days later, pain persisted, } \\
\text { worsened. Severe RUQ tenderness. } \\
\text { Leukocytes } 18,300 / \mathrm{mm}^{3} \text {. CT- } \\
\text { gallstones, gallbladder wall thickened } \\
\text { with surrounding edema. Lipase, liver } \\
\text { tests increased. Cholecystitis, } \\
\text { pancreatitis. Cholecystectomy } \\
\text { (chronic cholecystitis with focal } \\
\text { gangrene)-recovered. Occasional IBS } \\
\text { symptoms during 7.2-year followup. }\end{array}$ \\
\hline $\begin{array}{l}12 \\
86 \mathrm{~F}\end{array}$ & $\begin{array}{l}\text { Presenting history, examination, temp } \\
\text { data unavailable. Leukocyte count not } \\
\text { done. Ciprofloxacin/metronidazole }\end{array}$ & None & $\begin{array}{l}\text { To ED } 3 \text { days later due to vomiting, } \\
\text { bloating after starting antibiotics. } \\
\text { CT-diverticulosis without } \\
\text { diverticulitis. Drug-induced } \\
\text { symptoms. Antibiotics stopped. } \\
\text { Recovered. Many visits for IBS } \\
\text { symptoms, depression, anxiety and } 3 \\
\text { more nondiagnostic CTs done for } \\
\text { abdominal pain before general decline } \\
\text { and death } 7.2 \text { years later. }\end{array}$ \\
\hline
\end{tabular}

CT, computed tomography; ED, emergency department; F, female; M, male; IBS, irritable bowel syndrome; LLQ, left lower quadrant; RUQ, right upper quadrant; T, temperature.

Revised Diagnoses in Bold.

diverticulitis. In view of the common uncertainty of outpatient diverticulitis diagnosis and safety of treating many documented cases without antibiotics, it is advisable to consider withholding these drugs in suspected cases. Further research could aim to identify clinical features that improve the accuracy of clinical diagnosis in primary care.

To see this article online, please go to: http://jabfm.org/content/ 33/4/549.full.

\section{References}

1. Lacy BE, Mearin F, Chang L, et al. Bowel disorders. Gastroenterology 2016;150:1393-1407.e5.

2. Peery AF, Keku TO, Martin CF, et al. Distribution and characteristics of colonic diverticula in a United States screening population. Clin Gastroenterol Hepatol 2016;14:980-5.

3. Shahedi K, Fuller G, Bolus R, et al. Long-term risk of acute diverticulitis among patients with incidental diverticulosis found during colonoscopy. Clin Gastroenterol Hepatol 2013;11:1609-13.

4. Peery AF, Crockett SD, Murphy CC, et al. Burden of gastrointestinal, liver, and pancreatic diseases in the United States: update 2018. Gastroenterology 2019;156:254-77.

5. Iyer R, Longstreth GF, Chu LH, et al. Acute colonic diverticulitis: diagnostic evidence, demographic and clinical features in three practice settings. JGLD 2014;23:379-87.

6. O'Connor ES, Leverson G, Kennedy G, Heise CP. The diagnosis of diverticulitis in outpatients: on what evidence? J Gastrointest Surg 2010;14:303-8.

7. Chaudhary NA, Truelove SC. The irritable colon syndrome. A study of the clinical features, predisposing causes, and prognosis in 130 cases. Q J Med 1962;31:307-22.

8. Longstreth GF, Iyer RL, Chu LH, et al. Acute diverticulitis: demographic, clinical and laboratory features associated with computed tomography findings in 741 patients. Aliment Pharmacol Ther 2012;36:886-94.

9. Feuerstein JD, Falchuk KR. Diverticulosis and diverticulitis. Mayo Clin Proc 2016;91:1094-104.

10. Konvolinka CW. Acute diverticulitis under age forty. Am J Surg 1994;167:562-5.

11. Young-Fadok BM. Diverticulitis. N Engl J Med 2018;379:1635-42.

12. Longstreth GF, Tieu RS. Clinically diagnosed acute diverticulitis in outpatients: Misdiagnosis in 
patients with irritable bowel syndrome. Dig Dis Sci 2016;61:578-88.

13. Koebnick C, Langer-Gould AM, Gould MK, et al. Sociodemographic characteristics of members of a large, integrated health care system; comparison with US Census Bureau data. Perm J 2012;16: $37-41$.

14. Longstreth GF, Yao JF. Irritable bowel syndrome and surgery: a multivariable analysis. Gastroenterlogy 2004;126:1665-73.

15. Kawatkar A, Chu LH, Iyer R, et al. Development and validation of algorithms to identify acute diverticulitis. Pharmacoepidemiol Drug Saf 2015;24:27-37.

16. Jung HK, Choung RS, Locke GR, et al. Diarrheapredominant irritable bowel syndrome is associated with diverticular disease: a population-based study. Am J Gastroenterol 2010;105:652-61.

17. Järbrink-Sehgal ME, Andreasson A, Talley NJ, Agreus L, Song JY, et al. Symptomatic diverticulosis is characterized by loose stools. Clin Gastroenterol Hepatol 2016;14:1763-70.

18. O'Connor ES, Smith MA, Heise CP. Outpatient diverticulitis: mild or myth? J Gastrointest Surg 2012;16:1389-96.

19. Longstreth GF, Burchette RJ. Family practitioners' attitudes and knowledge about irritable bowel syndrome. Effect of a trial of physician education. Fam Pract 2003;20:670-4.

20. Mujagic Z, Jonkers D, Hungin APS, et al. Use of the Rome criteria for the diagnosis of irritable bowel syndrome in primary care: a survey among European countries. Eur J Gastroenterol Hepatol 2017;29:651-6.

21. Spiegel BMR, Farid M, Esrailian E, Talley J, Chang L, et al. Is irritable bowel syndrome a diagnosis of exclusion? A survey of primary care providers, gastroenterologists, and IBS experts. Am J Gastroenterol 2010;105:848-58.

22. Bharucha AE, Chakraborty S, Sletten CD. Common functional gastroenterological disorders associated with abdominal pain. Mayo Clin Proc 2016;91:1118-32.

23. El Serag HB, Pilgrim P, Schoenfeld P. Systemic review: natural history of irritable bowel syndrome. Aliment Pharmacol Ther 2004;19:861-70.

24. Whitehead WE, Palsson OS, Levy RR, Feld AD, Turner MJ, Von Korff M. Comorbidity in irritable bowel syndrome. Am J Gastroenterology 2007;102: 2767-76.

25. Barsky AJ, Borus JF. Functional somatic syndromes. Ann Intern Med 1999;130:910-21.

26. Longstreth GF, Drossman DA. Severe irritable bowel and functional abdominal pain syndromes: managing the patient and health care costs. Clin Gastroenterol Hepatol 2005;3:397-400.

27. Van Oudenhove LV, Levy RL, Crowell MD, et al. Biopsychosocial aspects of functional gastrointestinal disorders: how central and environmental processes contribute to the development and expression of functional gastrointestinal disorders. Gastroenterology 2016;150:1355-67.

28. Strate LL, Peery AF, Neumann I. American Gastroenterological Association Institute technical review on the management of diverticulitis. Gastroenterology 2015;149:1950-76.

29. Dijk ST, Daniels L, Unlu C, et al. Long-term effects of omitting antibiotics in uncomplicated acute diverticulitis. Am J Gastroenterol 2018;113:1045-52.

30. Longstreth GF, Chen Q, Wong C, Yao JF. Increased systemic antibiotic use and Clostridium difficile infection among outpatients with irritable bowel syndrome. Clin Gastroenterol Hepatol 2018;16:974-6.

31. Dingle KE, Didelot X, Quan TP, et al. Effects of control interventions on Clostridium difficile infection in England: an observational study. The Lancet Infectious Diseases 2017;17:411-21.

32. Palsson OS, Baggish J, Whitehead WE. Episodic nature of symptoms in irritable bowel syndrome. Am J Gastroenterol 2014;109:1450-60. 
Appendix. Colon radiologic and endoscopic imaging procedures that revealed no diverticulosis in 29 outpatients with irritable bowel syndrome whose presenting symptoms were treated with antibiotics as diverticulitis and not revised to another etiology or excluded by computed tomography. Individual patients are indicted by horizontal lines depicting health plan membership. Lines beginning at the onset of 1998 indicate membership starting then or earlier, and a terminal " $\mathrm{x}$ " indicates death. Age is at diagnosis of diverticulitis. F, female; M, Male.

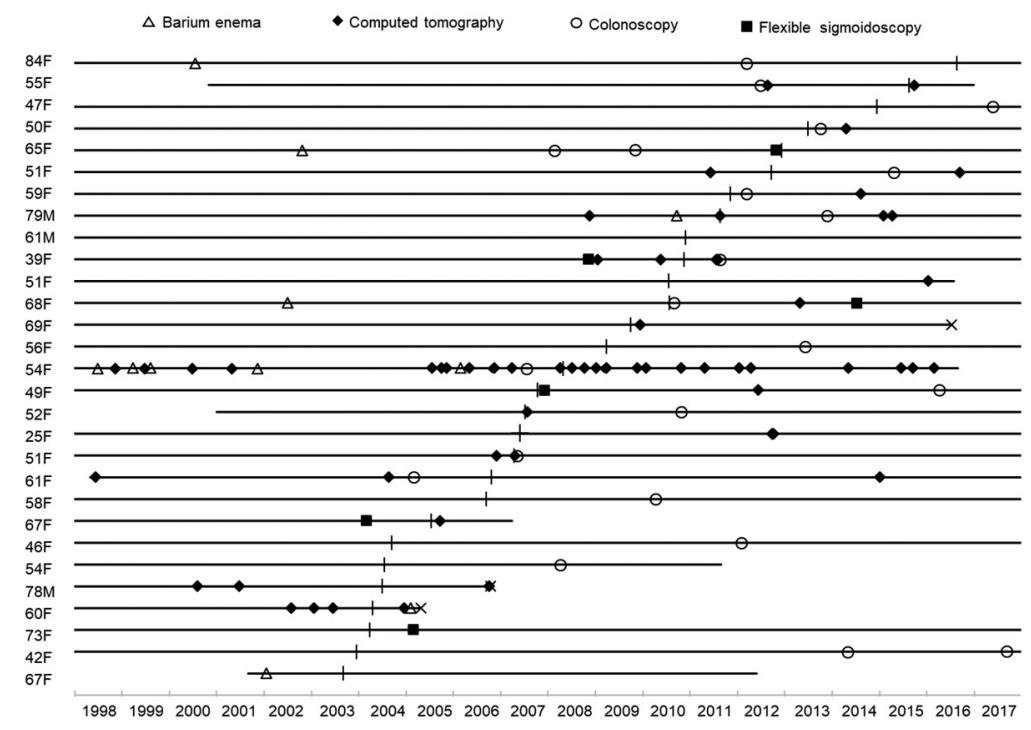

